\title{
End of Life Communication with Patient's Family: Challenges and Opportunities for Nurses
}

\author{
Yusrita Zolkefli ${ }^{*}$, Latifah Jehloh ${ }^{2}$ \\ 1PAPRSB Institute of Health Sciences, Universiti Brunei Darussalam. \\ ${ }^{2}$ Faculty of Nursing, Princess of Naradhiwas University, Thailand. \\ *E-mail: yusrita.zolkefli@ubd.edu.bn
}

\section{Dear Editor,}

Communication with dying patients and families is mainly regarded as complex and has been described as similar to addressing "the elephant in the room" (1). However, nurses' delivery of effective and caring communication is deemed essential to establishing therapeutic relationship with families, providing families with accurate and consistent information about the patient's diagnosis and treatment, and empowering families to make informed decisions (2). Nurses spend much time with patients while providing end of life care, so they have numerous opportunities to engage in meaningful interactions with them and their families (3). Unfortunately, research shows that nurses communicate ineffectively during end-of-life care in a variety of settings, including hospitals (4), primary care (5) and outpatient departments (6).

When dealing with persons who have lifelimiting illnesses and their families, nurses face numerous problems. There are three types of obstacles: nurse-related challenges, patient and family caregiver-related challenges, and organisational-related challenges (3). The nurse-related challenges highlight how nurses are underprepared to undertake difficult conversations because they lack a communication skill set and framework to respond to difficult questions, obtain information, deal with intense emotions, and engage with patients' families (7). In the patient and family caregiver-related challenges, some variables that contribute to the complexity of care and interaction with family members include frequent interruptions for updated information on the patient's condition (8), unrealistic and misaligned expectations, and unmet patient values and needs. Furthermore, organisational-related challenges include lack of patient's information and time limit the ability of nurses to engage in meaningful dialogues with patients and their families (3). These challenges may have contributed to nurses' emotional burden to cope with daily (9). Such challenges create frustrations and feelings of unpreparedness among the nurses and feel constrained. Nurses also described fatigue, staff shortages, or work pressures as justifying their critical behaviours in confronting the families (10).

These challenges suggest several opportunities for nursing practice. First, the inadequate preparedness suggests that end of life communication training is crucial for developing relevant communication skills (11). Nurses who had actively acquired knowledge through education and access to literature showed more substantial commitment to providing emotional support in interpersonal relations and making patientand family-focused decisions (7). Second, nurses are in a unique position to facilitate and improve care for dying patients and their families by providing information, facilitating discussion, advocating for the patient's wishes, and assisting them in decision making (12). Third, a recent study posited that families might be a source of information on the quality of end of life communication provided at ICUs. Their perception of communication, decision-making, nursing care, the ICU 
environment, and spiritual support substantially impacts whether or not they are satisfied with the care at ICUs. Personalised and regular communication, support in decision-making, compassionate nursing care, a warm and family-friendly environment and spiritual support could help families cope with their loss and increase their satisfaction with end of life communication (13). Fourth, the gaps in the communication suggest that an emphasis on effective communication between health care professionals. Better communication among nurses, doctors, and families was the most frequent remark to build a supportive environment for end of life communication (14). Fifth, nurses' professional and ethical sensitivity in dealing with patients' families at the end of life are needed to enhance effective communication in providing quality care to families (10).

We can only hope to improve communication with families, mainly when they want to know what is happening. It is hoped that nurse managers will consider means to respond adequately to both the nurses' and families' needs and, at the same time, not neglect the preparation and support needed by nurses. At the same time, the decreasing workload would help nurses spend more time with the patient and consequently provide better care. It is not too soon - or too late - to set up teams of nurses to act as mentors and conduits of meaningful communication between nurses and families in each care facility. Most importantly, such communication must be carried out competently. The nurses must be committed to supporting and preserving the continuity of psychosocial care at a level that benefits both patients and their families. It is also not too late to invite and listen carefully to the narratives and concerns of the nurses and provide extensive support and education, where and when it is needed.

\section{Article History:}

Submitted: 05 December 2021

Accepted: 29 January 2022

Published: 31 January 2022

ISSN: $2600-898 X$

\section{REFERENCES}

1. Betcher DK. Elephant in the room project: improving caring efficacy through effective and compassionate communication with palliative care patients. Medsurg Nurs. 2010; 19(2):101-5.

2. Angelini DJ. Interdisciplinary and interprofessional education: What are the key issues and considerations for the future? J Perinat Neonatal Nurs. 2011; 25(2):175-9.

3. Kerr D, Milnes S, Ammentorp J, McKie C, Dunning T, Ostaszkiewicz $J$ et al. Challenges for nurses when communicating with people who have lifelimiting illness and their families: A focus group study. J. Clin. Nurs. 2019; 1-13.

4. Feder SL, Britton MC, Chaudhry SI (2018). They need to have an understanding of why they're coming here and what the outcomes might be". Clinician perspectives on goals of care for patients discharged from hospitals to skilled nursing facilities. J Pain Symptom Manage. 2018; 55(3); 930-37.

5. Ellington L, Reblin M, Clayton MF, Berry P, Mooney KJ. Hospice nurse communication with patients with cancer and their family caregivers. J Palliat Med. 2012; 15(3): 26268.

6. Golsäter M, Enskär K, Knutsson S. Parents' perceptions of how nurses care for children as relatives of an ill patient - Experiences from an oncological outpatient department. Eur J Oncol Nurs. 2019; 39: 3540.

7. Ranse K, Yates P, Coyer F. Modelling endof-life care practices: Factors associated with critical care nurse engagement in care provision. Intensive Crit Care Nurs. 2016; 33:48-55.

8. Beckstrand RL, Smith MD, Heaston S, Bond AE. Emergency nurses' perceptions of size, frequency, and magnitude of obstacles and supportive behaviors in endof-life care. J Emerg Nurs. 2008; 34(4):290300.

9. DeSanto-Madeya S, Safizadeh P. Family satisfaction with end-of-life care in the intensive care unit: A systematic review of the literature: A systematic review of the literature. Dimens Crit Care Nurs. 2017; 36(5):278-83. 
10. Norouzadeh R, Anoosheh M, Ahmadi F. Nurses' communication with the families of patients at the end-of-life. Omega (Westport). 2020; 30222820959933.

11. Anderson WG, Puntillo K, Boyle D, Barbour S, Turner K, Cimino J, et al. ICU bedside nurses' involvement in palliative care communication: A multicenter survey. J Pain Symptom Manage. 2016; 51(3):589596.e2.

12. Zomorodi M, Lynn MR. Critical care nurses' values and behaviors with end- oflife care: perceptions and challenges. J Hosp Palliat Nurs. 2010; 12 (2): 89-96

13. Ozga D, Woźniak K, Gurowiec PJ. Difficulties perceived by ICU nurses providing end-of-life care: A qualitative study. Glob Adv Health Med. 2020; 9:2164956120916176.

14. Hansen L, Goodell TT, Dehaven J, Smith M. Nurses' perceptions of end-of-life care after multiple interventions for improvement. Am J Crit Care. 2009; 18(3):263-71; quiz 272. 